\title{
Comparative Studies on the Effects of Ethyl Nitrite and Hexyl Nitrite Induced Hemoglobin Oxidation of Diabetics Blood and Normal Blood
}

\author{
John Philip Tarburton* \\ National University, Department of Mathematics and Natural Sciences, 5245 Pacific Concourse Drive, Los \\ Angeles, California 90045, USA
}

\begin{abstract}
*Corresponding Author: John Philip Tarburton, National University, Department of Mathematics and Natural Sciences, 5245 Pacific Concourse Drive, Los Angeles, California 90045, USA. Email: jtarburton @nu.edu
\end{abstract}

\begin{abstract}
The effect of ethyl nitrite on human Type 2 diabetics blood was undertaken using non-diabetics blood as the control group. These studies revealed that diabetics erythrocytes were oxidized at a significantly greater rate than the control blood $(P<0.05)$. The ethyl nitrite mean oxidation time $\pm S E M$ of diabetics blood was $1.5 \pm 0.05 \mathrm{~min}$ (sample size $(n)$ is 20 ) and the mean oxidation time $\pm S E M$ of the non-diabetics blood was $4.5 \pm 0.05 \mathrm{~min}(n=20)$. Next the effect of hexyl nitrite on human Type 2 diabetics blood was undertaken using non-diabetics blood as the control group. It was revealed that diabetics erythrocytes were oxidized by hexyl nitrite at a significantly greater rate than control erythrocytes $(P<0.05)$. The mean oxidation time $\pm S E M$ of the diabetics blood was $1.5 \pm 0.04 \mathrm{~min}(n=20)$ whereas the mean oxidation time $\pm S E M$ of the non-diabetics blood was $3.7 \pm 0.07$ min $(n=20)$. Thus, these studies demonstrate that diabetics blood has an enhanced susceptibility of oxidation into methemoglobin by both ethyl nitrite and hexyl nitrite compared to their respective control groups. This similar finding could be attributed to the fact that both ethyl nitrite and hexyl nitrite are organic nitrites wherein the hexyl nitrite contains a saturated six hydrocarbon chain and ethyl nitrite contains a saturated two hydrocarbon chain. Thus the difference of four methylene molecules had no statistically significant effect on the rate of oxidation on either human diabetics blood or human non-diabetics blood $(P>0.05)$.
\end{abstract}

Keywords: Ethyl nitrite; Diabetes; HbA1C; Hemoglobin Oxidation; Hexyl nitrite; Methemoglobin.

\section{INTRODUCTION}

Both ethyl nitrite and hexyl nitrite belong to a class of compounds called alkyl nitrites that cause oxyhemoglobin to undergo oxidation, i.e. the iron (II) in the hemoglobin loses an electron to become iron (III) and cannot carry oxygen to the tissues and is therefore useless in oxygen transport to the tissues ${ }^{[1]}$. Nitrites are compounds that have long been known to induce this oxidation reaction ${ }^{[2]}$.

In addition both ethyl nitrite and hexyl nitrite are used as inhalants which are inexpensive and easy to obtain but can cause the heart to beat quickly and irregularly and then suddenly stop (cardiac arrest). An overdose via ingestion, rather than inhalation, may result in cyanosis and even death from methemoglobinemia ${ }^{[3-6]}$. With wide usage of alkyl nitrites for both medicinal and recreational uses and possible side effects there from a study of diabetics blood due to their increased susceptibility by amyl nitrite ${ }^{[7,8]}$ appears warranted.

\section{Materials AND MethodS}

Hexyl nitrite $(\geq 95 \%)$ was purchased from Fisher Scientific. Ethyl nitrite (10-20 wt. \% in ethanol) was purchased from the Sigma-Aldrich Chemicals Company. Other required chemicals were obtained from Fisher Scientific. Blood products such as normal adult blood and diabetics' blood were purchased from Physicians Plasma Alliance (PPA). The procedures followed by PPA for this sample collection study were in accordance with the ethical standards of the Hummingbird IRB Protocol wherein all subjects used in these studies gave voluntary informed consent. All blood was tested and certified to be non-viral by PPA.

For both alkyl nitrite studies: the data were obtained from 40 donors 20 of whom had type 2 
Comparative Studies on the Effects of Ethyl Nitrite and Hexyl Nitrite Induced Hemoglobin Oxidation of Diabetics Blood and Normal Blood

diabetes mellitus and 20 of whom were nondiabetics. The samples were provided as matched sets of diabetics and non-diabetics blood wherein the two groups were matched with respect to age, gender, number of obese and number of cigarette smokers as evenly as possible. Also these donors took similar vitamins and medications according to their medical histories. In Tables 1-4 the characteristics of the patients used in these studies are presented, i.e., $\mathrm{HbA1C}$, age, gender, weight and smoker status are noted. All blood was drawn into Acid-Citrate-Dextrose (ACD) tubes and stored at 2-4 $\mathrm{C}$ prior to use.

Table1. Characteristics of Diabetic Patients in the Ethyl Nitrite Oxidation Studies

\begin{tabular}{|l|l|l|l|l|l|l|}
\hline Sample ID & HbA1C & Age & Gender & Weight & Smoker status & $\begin{array}{l}\text { Oxidation } \\
\text { Time }\end{array}$ \\
\hline & $(\%)$ & $($ yrs $)$ & & $($ lbs $)$ & & $($ min) \\
\hline GWB002687 & 10.5 & 24 & Female & 258 & Non-Smoker & 1.4 \\
\hline GWB002677 & 11.2 & 22 & Male & 128 & Smoker & 1.3 \\
\hline GWB002685 & 11.6 & 42 & Female & 145 & Non-Smoker & 1.5 \\
\hline GWB002682 & 12 & 36 & Female & 174 & Smoker & 1.5 \\
\hline GWB002676 & 14.4 & 52 & Male & 136 & Non-Smoker & 1.6 \\
\hline GWB003977 & 11.3 & 47 & Female & 254 & Non-Smoker & 2.0 \\
\hline GWB003975 & 13.4 & 37 & Female & 175 & Smoker & 1.5 \\
\hline GWB003985 & 12.2 & 28 & Female & 206 & Non-Smoker & 1.9 \\
\hline GWB003978 & 13.9 & 48 & Male & 226 & Non-Smoker & 1.3 \\
\hline GWB003983 & 12.4 & 46 & Male & 288 & Non-Smoker & 1.8 \\
\hline GWB004097 & 10.0 & 43 & Female & 290 & Non-Smoker & 1.7 \\
\hline GWB004103 & 10.0 & 32 & Male & 236 & Smoker & 1.3 \\
\hline GWB004104 & 11.3 & 19 & Male & 282 & Non-Smoker & 1.7 \\
\hline GWB004116 & 14.7 & 29 & Male & 220 & Non-Smoker & 1.4 \\
\hline GWB004117 & 12.4 & 30 & Male & 241 & Non-Smoker & 1.4 \\
\hline GWB004119 & 12.4 & 40 & Male & 338 & Non-Smoker & 1.2 \\
\hline GWB004120 & 13.8 & 47 & Male & 400 & Smoker & 1.3 \\
\hline GWB004113 & 13.8 & 43 & Female & 136 & Smoker & 1.6 \\
\hline GWB004114 & 11.2 & 25 & Female & 258 & Non-Smoker & 1.4 \\
\hline GWB004123 & 11.5 & 31 & Male & 188 & Smoker & 1.3 \\
\hline Mean & 12.2 & 36.1 & & 229.0 & & 1.5 \\
\hline SEM & 0.31 & 2.14 & & 15.53 & & 0.05 \\
\hline
\end{tabular}

Table2. Characteristics of Non-diabetic Patients in the Ethyl Nitrite Studies

\begin{tabular}{|c|c|c|c|c|c|c|}
\hline Sample ID & HbA1C & Age & Gender & Weight & $\begin{array}{c}\text { Smoker } \\
\text { status }\end{array}$ & $\begin{array}{c}\text { Oxidation } \\
\text { Time }\end{array}$ \\
\hline & $(\%)$ & (yrs) & & (lbs) & & $(\min )$ \\
\hline GWB002712 & 5.6 & 24 & Male & 218 & Non-Smoker & 4.7 \\
\hline GWB002713 & 5.1 & 41 & Male & 196 & Non-Smoker & 5 \\
\hline GWB002714 & 5.6 & 58 & Male & 204 & Non-Smoker & 5 \\
\hline GWB002708 & 5.6 & 62 & Male & 225 & Non-Smoker & 4.3 \\
\hline GWB002709 & 6 & 48 & Male & 195 & Smoker & 4.2 \\
\hline ESG000232 & 5.3 & 27 & Male & 168 & Non-Smoker & 4.3 \\
\hline ESG000239 & 4.9 & 35 & Male & 217 & Non-Smoker & 4.3 \\
\hline ESG000235 & 5.6 & 25 & Male & 191 & Non-Smoker & 4.6 \\
\hline ESG000237 & 5.3 & 38 & Female & 192 & Smoker & 4.6 \\
\hline ESG000234 & 5.6 & 20 & Male & 240 & Smoker & 4.3 \\
\hline GWB004098 & 5.5 & 57 & Female & 236 & Non-Smoker & 4.3 \\
\hline GWB004099 & 5.5 & 31 & Male & 131 & Smoker & 4.3 \\
\hline GWB004100 & 5.5 & 35 & Male & 228 & Non-Smoker & 5 \\
\hline GWB004102 & 5.3 & 20 & Female & 146 & Smoker & 4.5 \\
\hline GWB004107 & 5.4 & 39 & Male & 197 & Non-Smoker & 4.4 \\
\hline GWB004145 & 5.5 & 35 & Male & 178 & Non-Smoker & 4.6 \\
\hline GWB004110 & 5.5 & 53 & Female & 160 & Non-Smoker & 4.6 \\
\hline GWB004115 & 5.5 & 57 & Male & 190 & Non-Smoker & 4.5 \\
\hline GWB004118 & 5.5 & 65 & Male & 174 & Non-Smoker & 4.6 \\
\hline GWB004121 & 5.4 & 25 & Female & 285 & Smoker & 4.6 \\
\hline
\end{tabular}


Comparative Studies on the Effects of Ethyl Nitrite and Hexyl Nitrite Induced Hemoglobin Oxidation of Diabetics Blood and Normal Blood

\begin{tabular}{|c|c|c|c|c|c|c|}
\hline Mean & 5.5 & 39.8 & & 198.6 & & 4.5 \\
\hline SEM & 0.05 & 3.19 & & 7.73 & & 0.05 \\
\hline
\end{tabular}

Table3. Characteristics of Diabetic Patients in the Hexyl Nitrite Studies

\begin{tabular}{|c|c|c|c|c|c|c|}
\hline Sample ID & HbA1C & Age & Gender & Weight & $\begin{array}{c}\text { Smoker } \\
\text { status }\end{array}$ & $\begin{array}{c}\text { Oxidation } \\
\text { Time }\end{array}$ \\
\hline & $(\%)$ & $($ yrs $)$ & & $($ lbs $)$ & & $($ min $)$ \\
\hline GWB002687 & 10.5 & 24 & Female & 258 & Non-Smoker & 1.3 \\
\hline GWB002677 & 11.2 & 22 & Male & 128 & Smoker & 1.5 \\
\hline GWB002685 & 11.6 & 42 & Female & 145 & Non-Smoker & 1.4 \\
\hline GWB002682 & 12 & 36 & Female & 174 & Smoker & 1.3 \\
\hline GWB003977 & 11.3 & 47 & Female & 254 & Non-Smoker & 1.5 \\
\hline GWB003975 & 13.4 & 37 & Female & 175 & Smoker & 1.8 \\
\hline GWB003985 & 12.2 & 28 & Female & 206 & Non-Smoker & 1.8 \\
\hline GWB003978 & 13.9 & 48 & Male & 226 & Non-Smoker & 1.8 \\
\hline GWB003983 & 12.4 & 46 & Male & 288 & Non-Smoker & 1.6 \\
\hline GWB004097 & 10.0 & 43 & Female & 290 & Non-Smoker & 1.5 \\
\hline GWB004103 & 10.0 & 32 & Male & 236 & Smoker & 1.7 \\
\hline GWB004104 & 11.3 & 19 & Male & 282 & Non-Smoker & 1.7 \\
\hline GWB004116 & 14.7 & 29 & Male & 220 & Non-Smoker & 1.4 \\
\hline GWB004117 & 12.4 & 30 & Male & 241 & Non-Smoker & 1.5 \\
\hline GWB004119 & 12.4 & 40 & Male & 338 & Non-Smoker & 1.3 \\
\hline GWB004120 & 13.8 & 47 & Male & 400 & Smoker & 1.4 \\
\hline GWB004113 & 13.8 & 43 & Female & 136 & Smoker & 1.5 \\
\hline GWB004114 & 11.2 & 25 & Female & 258 & Non-Smoker & 1.3 \\
\hline GWB004123 & 11.5 & 31 & Male & 188 & Smoker & 1.3 \\
\hline Mean & 12.2 & 36.1 & & 229.0 & & 1.5 \\
\hline SEM & 0.31 & 2.14 & & 15.53 & & 0.04 \\
\hline
\end{tabular}

Table4. Characteristics of Non-diabetic Patients in the Hexyl Nitrite Studies

\begin{tabular}{|c|c|c|c|c|c|c|}
\hline Sample ID & HbA1C & Age & Gender & Weight & $\begin{array}{c}\text { Smoker } \\
\text { status }\end{array}$ & $\begin{array}{c}\text { Oxidation } \\
\text { Time }\end{array}$ \\
\hline & $(\%)$ & (yrs) & & (lbs) & & $(\min )$ \\
\hline GWB002712 & 5.6 & 24 & Male & 218 & Non-Smoker & 4.5 \\
\hline GWB002713 & 5.1 & 41 & Male & 196 & Non-Smoker & 4 \\
\hline GWB002714 & 5.6 & 58 & Male & 204 & Non-Smoker & 3.7 \\
\hline GWB002708 & 5.6 & 62 & Male & 225 & Non-Smoker & 4 \\
\hline GWB002709 & 6 & 48 & Male & 195 & Smoker & 4.3 \\
\hline ESG000232 & 5.3 & 27 & Male & 168 & Non-Smoker & 3.5 \\
\hline ESG000239 & 4.9 & 35 & Male & 217 & Non-Smoker & 3.5 \\
\hline ESG000235 & 5.6 & 25 & Male & 191 & Non-Smoker & 3.2 \\
\hline ESG000237 & 5.3 & 38 & Female & 192 & Smoker & 3.5 \\
\hline ESG000234 & 5.6 & 20 & Male & 240 & Smoker & 3.8 \\
\hline GWB004098 & 5.5 & 57 & Female & 236 & Non-Smoker & 3.4 \\
\hline GWB004099 & 5.5 & 31 & Male & 131 & Smoker & 3.6 \\
\hline GWB004100 & 5.5 & 35 & Male & 228 & Non-Smoker & 3.7 \\
\hline GWB004102 & 5.3 & 20 & Female & 146 & Smoker & 3.7 \\
\hline GWB004107 & 5.4 & 39 & Male & 197 & Non-Smoker & 3.5 \\
\hline GWB004145 & 5.5 & 35 & Male & 178 & Non-Smoker & 3.8 \\
\hline GWB004110 & 5.5 & 53 & Female & 160 & Non-Smoker & 3.8 \\
\hline GWB004115 & 5.5 & 57 & Male & 190 & Non-Smoker & 3.9 \\
\hline GWB004118 & 5.5 & 65 & Male & 174 & Non-Smoker & 3.7 \\
\hline GWB004121 & 5.4 & 25 & Female & 285 & Smoker & 3.7 \\
\hline Mean & 5.5 & 39.8 & & 198.6 & & 3.7 \\
\hline SEM & 0.05 & 3.19 & & 7.73 & & 0.07 \\
\hline
\end{tabular}

The Hemoglobin A1C (HbA1C) percentages were determined using a Bayer DCA-2000 test kit. Diabetes was assessed as a HbA1C ARC Journal of Diabetes and Endocrinology percentage greater than $6.5 \%{ }^{[9]}$. A laboratory spectrophotometer equipped with a strip chart recorder was employed to monitor the formation 
of methemoglobin at $436 \mathrm{~nm}$. A small table top centrifuge was used to separate plasma from the red blood cells. To determine the oxidation times blood samples were centrifuged for $2000 \mathrm{~g}$ for $20 \mathrm{~min}$ to remove any remaining plasma. The remaining packed Red Blood Cells (RBCs) were aerated and washed in $20 \mathrm{mM}$ Phosphate Buffer Saline (PBS) at pH 7.2 followed by another centrifugation to remove the saline. This procedure of centrifugation, aeration and washing was repeated. The RBCs were then resuspended in $20 \mathrm{mM}$ PBS $(\mathrm{pH}$ 7.2) for a maximum of $60 \mathrm{~min}$ prior to testing.

A $0.01 \mathrm{~mL}$ portion of resuspended RBCs was hemolyzed by the addition of $1.0 \mathrm{~mL}$ of distilled water and adjusted to a final volume of $2.6 \mathrm{~mL}$ by the addition of $20 \mathrm{mM}$ PBS ( $\mathrm{pH} 7.2$ ). The hemoglobin solutions were then adjusted to a standard absorbance (e.g., $\mathrm{A}=1.0 \pm 0.2$ ) at a wavelength of $436 \mathrm{~nm}$ with more $20 \mathrm{mM}$ PBS (pH 7.2). The $2.6 \mathrm{~mL}$ aliquot of this hemoglobin solution was then added to a $0.05 \mathrm{~mL}$ aliquot of $0.1 \%$ ethyl nitrite (or $0.1 \%$ hexyl nitrite) in ethanol solution. A final concentration of 38 $\mu \mathrm{mol} / \mathrm{L}$ of ethyl nitrite (or $138 \mu \mathrm{mol} / \mathrm{L}$ for hexyl nitrite) was obtained after its addition to the hemoglobin solution. In both studies the above gave a final hemoglobin concentration between 6 and $9 \mu \mathrm{mol} / \mathrm{L}^{[10]}$.

All of the above solutions were then placed in cuvettes and the reaction measured in a spectrophotometer equipped with a chart recorder set at a wavelength of $436 \mathrm{~nm}$. This is a suitable wavelength for measuring and distinguishing oxyhemoglobin and methemoglobin. The spectrophotometer chart recorder then generated graphic representations of the conversion of oxyhemoglobin into methemoglobin as a function of time. The terminal period or asymptotic phase corresponds to essentially $100 \%$ methemoglobin formation. The final absorbance was found to be approximately $\mathrm{A}=0.5 \pm 0.1$. All hemoglobin oxidation times (in $\min$ ) obtained have been included in Tables 1-4 for these samples.

According to Colton ${ }^{[11]}$ the appropriate test to use for these data is the Student's t-test for independent samples. The data was analyzed using an Excel spreadsheet on a Microsoft computer. The significance level has been considered to be $\mathrm{P}<0.05$.

\section{RESULTS AND DISCUSSION}

For the alkyl nitrite studies the findings of the $\mathrm{HbA1C}$ percentages revealed that the diabetics blood mean \pm standard error of the mean (SEM) was12.2 $\pm 0.31 \%$, while that of the nondiabetics blood had a mean \pm SEM of $5.5 \pm$ $0.05 \%$. Thus, the percentage differences between the two populations was statistically significant $(\mathrm{P}<0.05)$, and this means that these two populations are good groups on which to undertake the alkyl nitrite oxidation studies as is shown in the column comparison of the means \pm SEM in Figure 1 [11]. For ethyl nitrite the mean oxidation time of the diabetics blood \pm SEM was $1.5 \pm 0.05 \mathrm{~min}$ whereas the mean oxidation times of the non-diabetics blood \pm SEM was 4.5 \pm 0.05 min as shown in the column comparison of the mean \pm SEM in Figure 2. Based on an independent Student's t-test, the time taken for diabetics erythrocytes to undergo oxidation was significantly shorter $(\mathrm{P}<0.05)$ than the nondiabetic controls.

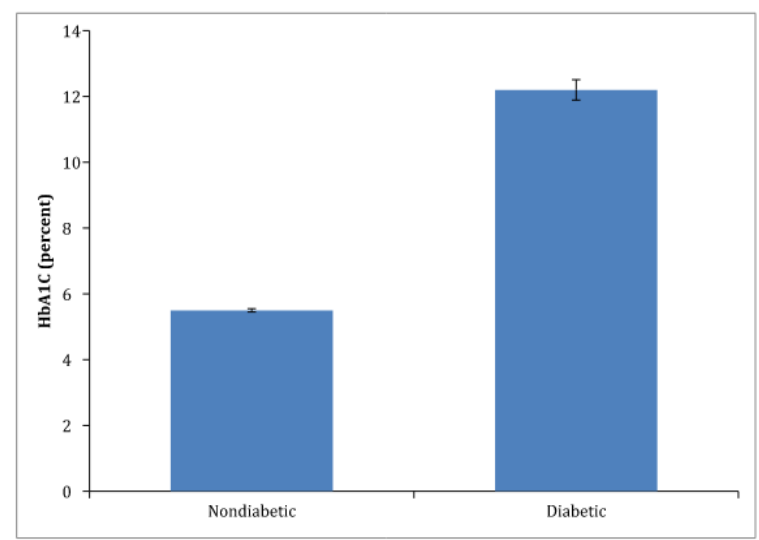

Figure1. Column comparison of means for the percent HbAlC of the hemoglobin of diabetics and non-diabetics blood used in the alkyl nitrite studies

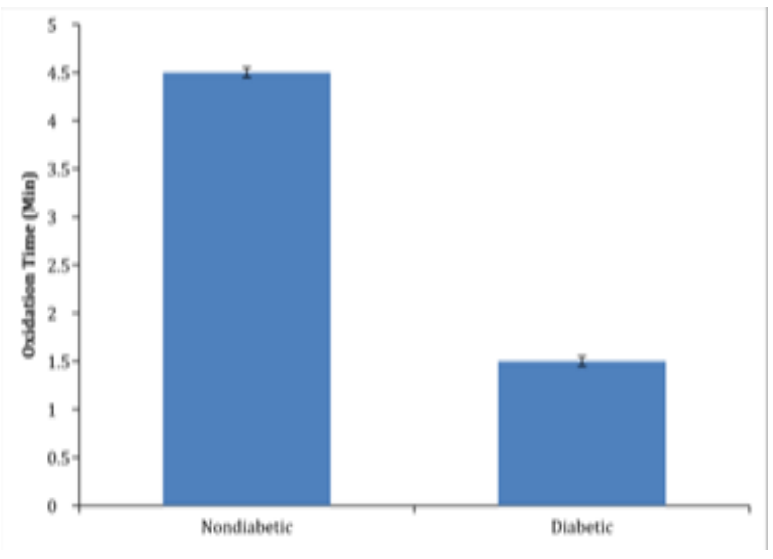

Figure2. Column comparison of means for the oxidation times of the hemoglobin of diabetics and non-diabetics blood by ethyl nitrite

For hexyl nitrite the mean oxidation time \pm SEM of the diabetics blood was $1.5 \pm 0.04 \mathrm{~min}$ whereas the mean oxidation times \pm SEM of the non-diabetics blood was $3.7 \pm 0.05 \mathrm{~min}$ as shown in the column comparison of the mean \pm SEM in Figure 3. Based on an independent 
Student's t-test, the time taken for diabetics erythrocytes to undergo oxidation was significantly shorter $(\mathrm{P}<0.05)$ than the nondiabetic controls. This similar finding could be attributed to the fact that both ethyl nitrite and hexyl nitrite are organic nitrites that contain saturated hydrocarbon chains.

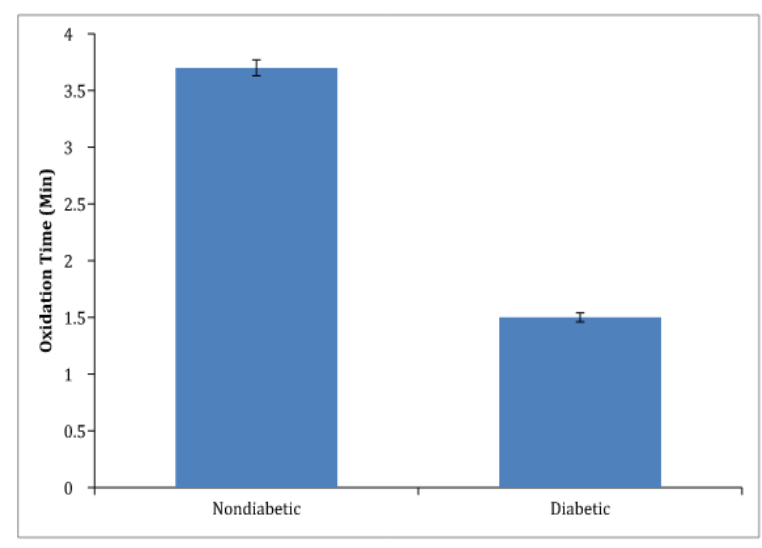

Figure3. Column comparison of means for the oxidation times of the hemoglobin of diabetics and non-diabetics blood by hexyl nitrite

Interestingly, the enhanced susceptibility to both alkyl nitrite induced oxidation reactions occurred in Type 2 diabetics blood which implies that $\mathrm{HbA1C}$ oxidation to methemoglobin is a direct function of the amount of HbA1C present as opposed to metabolic differences in the Type 1 and Type 2 diabetes [12]. Essentially, any untreated diabetic simply has a greater percentage of $\mathrm{HbA} 1 \mathrm{C}$ than a non-diabetic, e.g. $12.2 \%$ vs. $5.5 \%$ in this study as shown in Figure 1. Thus, these preliminary findings indicate that diabetics have hemoglobin that exhibit greater oxidative stress to alkyl nitrite owing to a higher percentage of $\mathrm{HbA1C}$.

\section{REFERENCES}

[1] Dan Longo, et al. (2012) Harrison's Principal's of Internal Medicine. 18th ed.. Vol. 1 McGraw Hill, New York, NY 857-858.

[2] Kiese M. Methemoglobinemia: a Comprehensive Treatise: Causes, Consequences, and Correction of Increased
Contents of Ferrihemoglobin in Blood. CRC Press. Cleveland, Ohio; 1974.

[3] Chilcote RR, Williams B, Wolff LJ, Baener RL (1977) Sudden death in an infant from methemoglobinemia after administration of "sweet spirits of nitre". Pediatrics 59:280-282.

[4] Bernasconi B, Konrad C, Fischer S (2014) Case Report - A dangerous intoxication after ingestion of alkyl nitrite ('poppers'). Anästhesiol Intensivmed Notfallmed Schmerzther 49: 654-658.

[5] Hall A, Stessel B, Bergmans D, Schnabel R (2012) Two cases of acquired methemoglobinemia. Acta Anaesth Belg 63:97-100.

[6] Clayton GD, Clayton FE (eds.) (1994) Three cases of ethyl nitrite intoxication have been reported. Patty's Industrial Hygiene and Toxicology. Volumes 2A-2F: Toxicology. 4th ed. John Wiley \& Sons, New York p 655.

[7] Tarburton J (2013) Amyl nitrite induced hemoglobin oxidation studies in diabetics and nondiabetics blood. J Diabetes and Metabolism 4: 258-260.

[8] Tarburton JP (2014) Hemoglobin oxidation studies in diabetics blood comparing the effect of sodium nitrite vs. amyl nitrite. Diabetes Research and Treatment 2014 1:112-117.

[9] National Diabetes Fact Sheet (2011) U.S. Department of Health and Human Services, Centers for Disease Control and Prevention.

[10] Weissbluth M (1974) Hemoglobin: Cooperativity and electronic properties. In: Kleinzellar A, Springer GF, Whitman HG (eds), Molecular Biology, Biochemistry and Biophysics, Vol 15 Sringer-Verlag, New York 136-141.

[11] Colton T. Statistics in Medicine. Little, Brown and Co. Boston, MA; 1974: pp. 99-150 and 207-211.

[12] Moussa SA (2008) Oxidative stress in diabetes mellitus. Romanian Journal of Biophysics 18: 225-236.

Citation: John Philip Tarburton, Comparative Studies on the Effects of Ethyl Nitrite and Hexyl Nitrite Induced Hemoglobin Oxidation of Diabetics Blood and Normal Blood, ARC Journal of Diabetes and Endocrinology. 2017; 3(1):1-5. doi:dx.doi.org/10.20431/2455-5983.0301001.

Copyright: () 2017 Authors. This is an open-access article distributed under the terms of the Creative Commons Attribution License, which permits unrestricted use, distribution, and reproduction in any medium, provided the original author and source are credited. 